\title{
Remodeling and spacing factor 1 overexpression is associated with poor prognosis in renal cell carcinoma
}

\author{
XIUWEI ZHANG ${ }^{1,2}$, DONGWEI XUE ${ }^{3}$, FENGXIA HAO $^{1}$, LINGLING XIE $^{1}$, JIANI HE $^{1}$, \\ JUNDA GAI $^{1}$, YUHUI LIU ${ }^{1}$, HONGTAO XU ${ }^{1}$, QINGCHANG LI ${ }^{1}$ and ENHUA WANG ${ }^{1}$ \\ ${ }^{1}$ Department of Pathology, The First Affiliated Hospital and College of Basic Medical Sciences of \\ China Medical University, Shenyang, Liaoning 110001; Departments of ${ }^{2}$ Pathology and ${ }^{3}$ Urology, \\ The Fourth Affiliated Hospital of China Medical University, Shenyang, Liaoning 110032, P.R. China
}

Received November 9, 2016; Accepted November 2, 2017

DOI: $10.3892 / 01.2018 .7797$

\begin{abstract}
The present study aimed to assess the expression and prognostic significance of remodeling and spacing factor 1 (RSF1; HBXAP) in renal cell carcinoma (RCC). RSF1 expression was analyzed using immunohistochemistry on tissue samples from a consecutive series of 137 patients with RCC who underwent tumor resection between November 2000 and March 2004. The associations between RSF1 expression, clinicopathological factors and patient survival were investigated. Immunohistochemistry revealed that RSF1 was highly expressed in $43.1 \%$ (59/137) of the RCC samples. RSF1 expression levels were associated with the T stage of the Tumor-Node-Metastasis grading system. Kaplan-Meier survival analysis indicated that high RSF1 expression in RCC was significantly associated with a poor prognosis. Multivariate analysis revealed that RSF1 expression is an independent prognostic parameter for the duration of overall survival of patients with RCC. The results demonstrated that a high expression level of RSF1 in RCC is associated with advanced tumor stages and a poor prognosis. To the best of our knowledge, the present study provides novel evidence of the biological significance of RSF1 expression in RCC.
\end{abstract}

\section{Introduction}

Renal cell carcinoma ( $\mathrm{RCC}$ ) is one of the most common malignant tumors of the kidney, accounting for 2-3\% of all malignant tumor types in adults worldwide in $2008(1,2)$. Its incidence and mortality rate continue to increase steadily $(1,3)$, causing a great threat to human health. Since the efficacy of radiation

Correspondence to: Dr Qingchang Li, Department of Pathology, The First Affiliated Hospital and College of Basic Medical Sciences of China Medical University, 155 Nanjing Road, Shenyang, Liaoning 110001, P.R. China

E-mail: liqc1972@126.com

Key words: remodeling and spacing factor 1, renal cell carcinoma, prognosis and chemotherapy treatment is limited (4), identifying novel molecular targets for therapy is crucial for RCC.

Remodeling and spacing factor 1 (RSF1), located at the 11 p13.5 locus, was originally identified as an interacting factor for hepatitis B virus (HBV) X antigen in host cells (5). This hepatitis $B$ virus $X$-associated protein (HBXAP), now termed RSF1, is a subunit of the ISWI chromatin-remodeling complex (6). Chromatin remodeling is a basic process in multiple critical biological activities, including nucleic acid synthesis, transcriptional regulation, DNA repair, methylation and recombination (7). Cancer may be caused by mutations of any of the chromatin remodeling key proteins, since this will result in the abnormal expression of genes (8-10). RSF1 is overexpressed and exhibits gene amplification in multiple solid tumors, including breast cancer, ovarian cancer and oral squamous cell carcinoma (11-13). Studies have indicated that overexpression and/or gene amplification of RSF1 in tumors is associated with proliferation, invasion and poor prognosis (14-18). Accumulating evidence suggests that $11 \mathrm{q} 13$ region gene amplification is closely associated with the development of malignant tumors (14-18). An oncogene in the 11q13 region is also overexpressed in RCC (19).

However, to the best of our knowledge, there has been no study examining the expression profile of RSF1 in RCC. To additionally identify markers that are associated with poor prognosis in RCC and to explore the molecular mechanisms that account for the aggressive behavior of RCC, the present study examined the expression status of RSF1 in RCC, and whether the level of RSF1 expression was associated with clinical outcomes in primary RCCs.

\section{Materials and methods}

Patients and specimens. The study protocol was approved by the Institutional Review Board of China Medical University (Shenyang, China) and written informed consent was obtained from all patients. Primary tumor specimens and corresponding normal tissues, which were at a distance of $2-5 \mathrm{~cm}$ from the tumor tissues, were obtained from 137 patients diagnosed with RCC during their first resection at the First Affiliated Hospital of China Medical University (Shenyang, China) between November 2000 and March 2004. There were 
76 males and 61 females, with an age range of 35-80 years and an average age of 60 years. Lymph node metastases and distant metastases were identified in 11 and 5 patients, respectively. None of the patients had received radiotherapy or chemotherapy prior to surgical resection. The specimens were fixed in $10 \%$ neutral formalin at room temperature overnight, embedded in paraffin, and stained with $0.2 \%$ hematoxylin and $0.5 \%$ eosin at room temperature for $5 \mathrm{~min}$ and $2 \mathrm{~min}$, respectively. The histological diagnosis and differentiation grade were evaluated according to the pathologic-Tumor-Node-Metastasis (TNM) staging system of the American Joint Committee on Cancer (20). There were 103, 17, 11 and 6 cases at stage I, II, III and IV, respectively.

Immunohistochemistry. Surgically excised tumor specimens were fixed in $10 \%$ neutral formalin at room temperature overnight and embedded in paraffin and $4-\mu \mathrm{m}$ thick sections were prepared. Immunostaining was performed using the avidin-biotin-peroxidase complex method (14) (UltraSensitive $^{\mathrm{TM}}$ SPMouse/RabbitIHC kit; Fuzhou Maixin Biotech Co., Ltd., Fuzhou, China). The sections were deparaffinized in xylene, rehydrated with graded alcohol $(100,95,80$ and $70 \%)$, and then boiled at $100^{\circ} \mathrm{C}$ in $0.01 \mathrm{M}$ citrate buffer ( $\mathrm{pH} \mathrm{6.0)}$ for $2 \mathrm{~min}$ in an autoclave. Hydrogen peroxide $(0.3 \%)$ was applied to block endogenous peroxide activity and the sections were incubated at room temperature for $1 \mathrm{~h}$ with normal goat serum (Fuzhou Maixin Biotech Co., Ltd.) to decrease nonspecific binding. Tissue sections were then incubated with anti-RSF1 mouse monoclonal antibody (1:1,500; cat no. N05-727; Upstate Biotechnology, Inc., Lake Placid, NY, US). Mouse IgG (dilution, 1:500; cat no. ab37355; Abcam, Cambridge, USA) was used as a negative control. Staining with anti-RSF1 mouse monoclonal antibody and mouse immunoglobulin was performed at room temperature for $2 \mathrm{~h}$. Biotinylated goat anti-mouse serum $\operatorname{IgG}$ (dilution, 1:500; cat no. SHB131; Beijing Solarbio Science \& Technology Co., Ltd., Beijing, China) was used as a secondary antibody. Subsequent to washing, the sections were incubated with streptavidin-biotin conjugated with horseradish peroxidase at $37^{\circ} \mathrm{C}$ for $30 \mathrm{~min}$ and the peroxidase reaction was developed with 3,3-diaminobenzidine tetrahydrochloride. Counterstaining with $0.2 \%$ hematoxylin was performed at room temperature for 5 minand the sections were successively dehydrated in 85 , 95 and $100 \%$ ethanol and dimethylbenzene prior to mounting.

A total of 2 independent investigators (Doctors at the Department of Pathology at the First Affiliated Hospital and College of Basic Medical Sciences of China Medical University, Liaoning, China) blinded to the clinical history examined all tumor slides randomly. A total of 5 views were examined per slide and 100 cells were observed per view at a magnification of x 200 or x400 (light microscope BX51; Olympus, Tokyo, Japan). Following the methods described previously, immunostaining of RSF1 was scored on a semi-quantitative scale by evaluating the percentage of immunoreactive tumor cells and staining intensity (21). Nuclear immunostaining in tumor cells was considered positive staining. The percentage of stained tumor cells was scored as $0,0 \% ; 1,1-5 \% ; 2,6-25 \% ; 3,26-75 \%$; and $4,76-100 \%$. The staining intensity was categorized as follows: 0 , negative or weak; 1, moderate; and 2, strong. The scores of each tumor
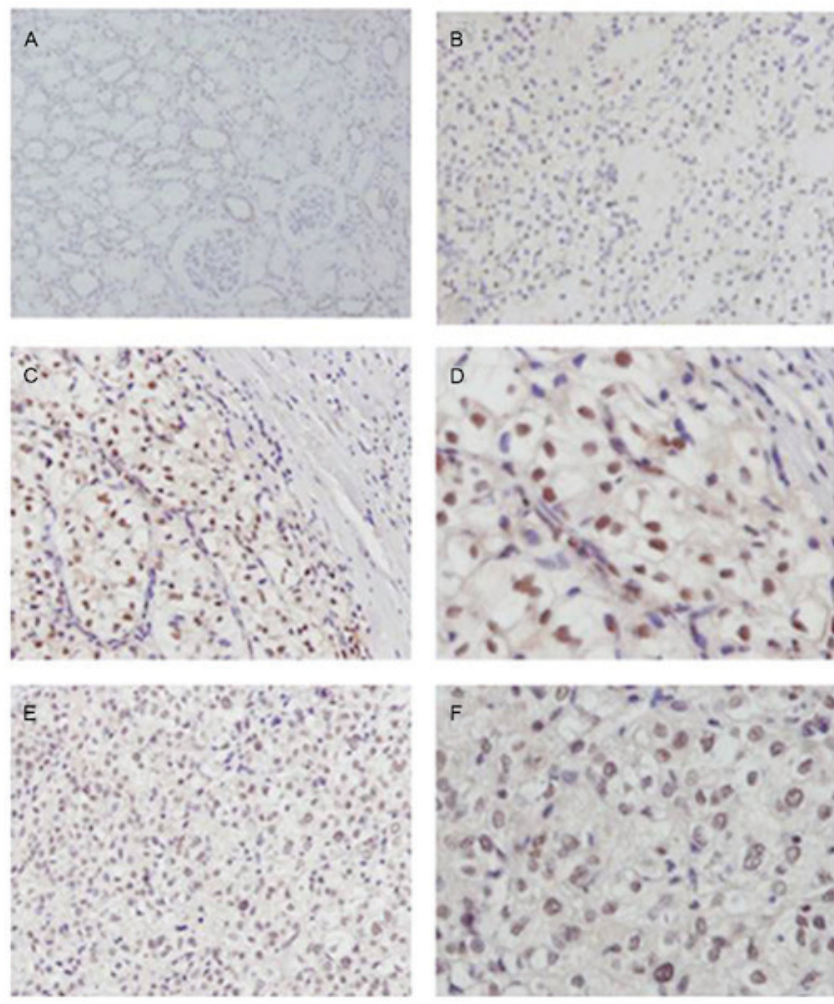

Figure 1. Representative immunohistochemistry images for RSF1 expression in RCC. (A) Negative RSF1 in normal renal tubular epithelium (magnification, x200). (B) Weak nuclear staining of RSF1 expression in a case of stage I RCC (magnification, x200). (C) Strong nuclear RSF1 staining in stage II RCC (magnification, x200). (D) Strong nuclear RSF1 staining in stage II RCC (magnification, $x 400$ ). (E) Strong nuclear RSF1 staining in stage III RCC (magnification, x200). (F) Strong nuclear RSF1 staining in stage III RCC (magnification, x400). RCC, renal cell carcinoma; RSF1, remodeling and spacing factor 1.

sample were multiplied to produce a final score of $0-8$, and the tumor samples with a final score of 4-8 were considered to represent high RSF1 expression. Weak/negative RSF1 staining with a final score $<4$ was considered to indicate low expression.

Statistical analysis. SPSS version 11.5 for Windows (SPSS, Inc., Chicago, IL, USA) was used for all analyses. A $\chi^{2}$ test was used to evaluate possible associations between RSF1 expression and clinicopathological factors. A Kaplan-Meier survival analysis was used to estimate the probability of patient survival; the differences in survival rates between the subgroups of patients were compared using Mantel's log-rank test. The univariate and multivariate analysis were performed using the Cox regression model to examine the effects of different variables on survival, respectively. The data were presented using the mean \pm standard deviation. All P-values were two-sided; $\mathrm{P}<0.05$ was considered to indicate a statistically significant difference.

\section{Results}

Expression and localization of RSF1 in RCCs. RSF1 protein expression was evaluated in a panel of 137 primary RCC samples and corresponding normal tissues using immunohistochemistry. Mouse IgG was used as a negative control. RSF1 was expressed at only low levels in normal renal 
Table I. Distribution of RSF1 status in human renal cell carcinoma according to clinicopathological characteristics.

\begin{tabular}{|c|c|c|c|c|}
\hline Characteristic & Number & Negative/weak RSF1 expression & RSF1 overexpression & P-value \\
\hline \multicolumn{5}{|l|}{ Age } \\
\hline$<60$ & 63 & 35 & 28 & \multirow[t]{2}{*}{0.763} \\
\hline$\geq 60$ & 74 & 43 & 31 & \\
\hline \multicolumn{5}{|l|}{ Sex } \\
\hline Female & 61 & 35 & 26 & \multirow[t]{2}{*}{0.925} \\
\hline Male & 76 & 43 & 33 & \\
\hline \multicolumn{5}{|l|}{ TNM stage } \\
\hline I & 103 & 68 & 35 & \multirow[t]{2}{*}{$0.049^{\mathrm{a}}$} \\
\hline II-IV & 34 & 16 & 18 & \\
\hline \multicolumn{5}{|l|}{ Tumor stage } \\
\hline $\mathrm{T} 1-2$ & 120 & 86 & 34 & \multirow[t]{2}{*}{$0.003^{\mathrm{a}}$} \\
\hline T3-4 & 17 & 6 & 11 & \\
\hline \multicolumn{5}{|l|}{ Nodal status } \\
\hline N0 & 126 & 77 & 49 & \multirow[t]{2}{*}{0.487} \\
\hline N1 & 11 & 5 & 6 & \\
\hline \multicolumn{5}{|l|}{ Metastasis } \\
\hline M0 & 132 & 82 & 50 & \multirow[t]{2}{*}{0.597} \\
\hline M1 & 5 & 2 & 3 & \\
\hline \multicolumn{5}{|l|}{ Nuclear grade } \\
\hline $1-2$ & 108 & 64 & 44 & \multirow[t]{2}{*}{0.289} \\
\hline $3-4$ & 29 & 14 & 15 & \\
\hline
\end{tabular}

P-value was obtained using a $\chi^{2}$ test. ${ }^{a} \mathrm{P}<0.05$ is considered to indicate a statistically significant difference (two-sided). RSF1, remodeling and spacing factor 1 ; TNM, tumor node metastasis.
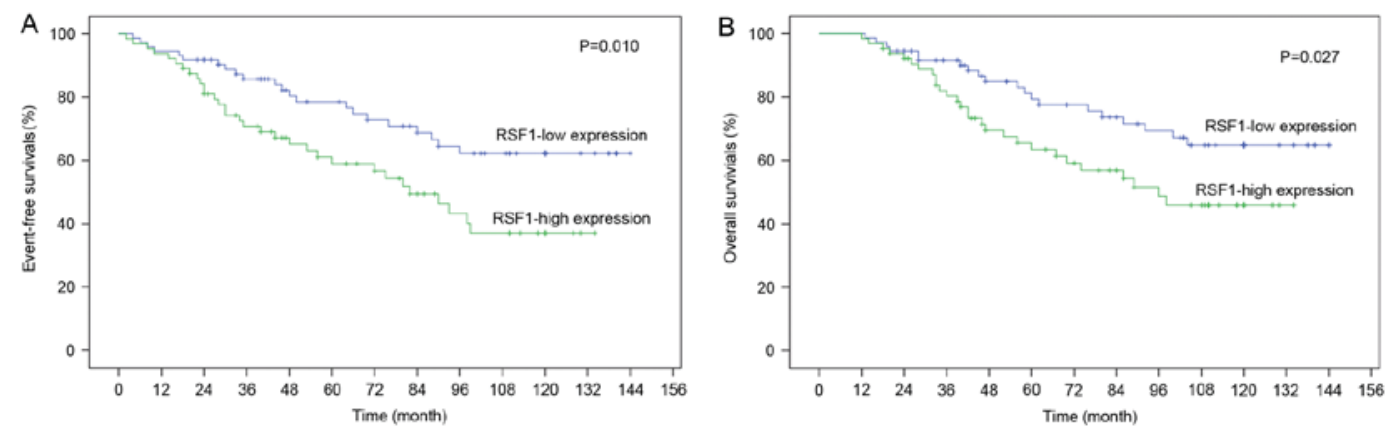

Figure 2. Positive RSF1 expression is associated with poor prognosis. (A) Kaplan-Meier event-free survival curves for patients with RCC stratified by expression of RSF1. Patients with a high RSF1 expression had more decreased event-free survival, compared with the patients with a low expression of RSF1. (B) Kaplan-Meier overall survival curves for patients with RCC stratified by expression of RSF1. Patients with a high RSF1 expression had decreased overall survival, compared with the patients with a low expression of RSF1. RCC, renal cell carcinoma; RSF1, remodeling and spacing factor $1 . \mathrm{P}<0.05$ is considered to indicate a statistically significant difference (two-sided).

tubular epithelium (Fig. 1A). Negative/weak nuclear expression was observed in stage I RCCs (Fig. 1B). High expression of RSF1 was identified in 59/137 (43.1\%) stage II and III RCCs (Fig. 1C-F).

Clinical significance of RSF1 protein expression in RCCs. The association between RSF1 expression and clinical features of patients and biological markers was analyzed. As summarized in Table I, no statistical association was identified between high RSF1 expression and age $(\mathrm{P}=0.763)$, lymph node metastasis
$(\mathrm{P}=0.487)$, metastasis $(\mathrm{P}=0.597)$ or nuclear grade $(\mathrm{P}=0.289)$. However, there was a significant association between high RSF1 expression and advanced TNM stage $(\mathrm{P}=0.049)$, which was more marked in advanced RCC stages (stage II-IV) compared with early stage (stage I) cases $(\mathrm{P}=0.003)$.

RSF1 protein expression is associated with prognosis and functions as an independent risk factor in RCCs. Whether the expression of RSF1 protein predicted that the overall and event-free survival of patients with RCC was additionally 
Table II. Univariate regression analysis in predicting the survival of patients with renal carcinoma.

\begin{tabular}{|c|c|c|c|c|}
\hline \multirow[b]{2}{*}{ Variable } & \multicolumn{2}{|c|}{ Event-free survival } & \multicolumn{2}{|c|}{ Overall survival } \\
\hline & HR (95\% CI) & P-value & HR (95\% CI) & P-value \\
\hline \multicolumn{5}{|l|}{ Age } \\
\hline$<60$ & $1.330(0.769-2.301)$ & 0.307 & $1.472(0.814-2.661)$ & 0.201 \\
\hline \multicolumn{5}{|l|}{$\geq 60$} \\
\hline \multicolumn{5}{|l|}{ Sex } \\
\hline Female & $1.042(0.603-1.803)$ & 0.882 & $1.175(0.650-2.124)$ & 0.593 \\
\hline \multicolumn{5}{|l|}{ Male } \\
\hline \multicolumn{5}{|c|}{ TNM stage } \\
\hline I & $8.030(3.643-17.702)$ & $<0.001^{\mathrm{a}}$ & $9.237(3.841-22.651)$ & $<0.001^{\mathrm{a}}$ \\
\hline \multicolumn{5}{|l|}{ II-IV } \\
\hline \multicolumn{5}{|c|}{ Tumor stage } \\
\hline $\mathrm{T} 1-2$ & $2.452(1.374-4.377)$ & $0.002^{\mathrm{a}}$ & $2.366(1.286-4.354)$ & $0.006^{\mathrm{a}}$ \\
\hline \multicolumn{5}{|l|}{ T3-4 } \\
\hline \multicolumn{5}{|c|}{ Nodal status } \\
\hline N0 & $6.845(3.702-12.657)$ & $<0.001^{\mathrm{a}}$ & $6.345(3.335-12.071)$ & $<0.001^{\mathrm{a}}$ \\
\hline \multicolumn{5}{|l|}{ N1 } \\
\hline \multicolumn{5}{|c|}{ Metastasis } \\
\hline M0 & $1.600(0.825-3.105)$ & 0.165 & $1.426(0.690-2.946)$ & 0.338 \\
\hline \multicolumn{5}{|l|}{ M1 } \\
\hline \multicolumn{5}{|c|}{ Nuclear grade } \\
\hline $1-2$ & $0.868(0.613-1.231)$ & 0.428 & $0.868(0.600-1.254)$ & 0.450 \\
\hline \multicolumn{5}{|l|}{$3-4$} \\
\hline \multicolumn{5}{|c|}{ RSF1 expression status } \\
\hline High & $2.019(1.171-3.481)$ & $0.012^{\mathrm{a}}$ & $1.889(1.063-3.358)$ & $0.030^{\mathrm{a}}$ \\
\hline Low & & & & \\
\hline
\end{tabular}

P-value was obtained using a $\chi^{2}$ text. ${ }^{\mathrm{a}} \mathrm{P}<0.05$ is considered to indicate a statistically significant difference (two-sided). HR, hazard ratio; CI, confidence interval; RSF1, remodeling and spacing factor 1; TNM, tumor node metastasis.

investigated. Through Kaplan-Meier analysis it was identified that patients with RSF1 expression exhibited significantly shorter event-free survival compared with those without RSF1 expression ( $\mathrm{P}<0.05$; Fig. 2A). Similarly, patients with low RSF1 expression levels exhibited significantly longer overall survival compared with those with high expression levels of RSF1 ( $\mathrm{P}<0.05$; Fig. 2B).

Whether RSF1 expression was an independent factor for patient survival was explored through univariate and multivariate Cox regression analyses. Univariate Cox regression analysis indicated that TNM stage, tumor stage, lymph node metastasis, and high RSF1 expression were associated with overall and event-free survival $(\mathrm{P}<0.05$; Table II). Multivariate Cox regression analysis demonstrated that TNM stage and RSF1 expression were independently associated with overall and event-free survival $(\mathrm{P}<0.05$; Table III).

\section{Discussion}

RSF1 (HBXAP) is a cellular nuclear protein that binds to sucrose non-fermenting protein 2 homolog, forming a chromatin remodeling protein complex termed RSF that mediates ATP-dependent chromatin remodeling and alters the chromatin structure or positioning of nucleosomes (22). Accumulating evidence indicates that chromatin remodeling is associated with the regulation of malignant cell transformation and tumor progression Amplification of genes at the 11q13.5 locus is common in solid tumors, including ovarian, head and neck, and breast carcinomas $(12,13,15,23-26)$. The genes of the region include RSF1, EMSY, BRCA2 interacting transcriptional repressor, P21 (RAC1) activated kinase 1 (PAK1), RAD9 checkpoint clamp component A, and cyclin D1 have been proposed as candidate tumor driver genes $(12,13,15,23-26)$. Numerous studies have demonstrated that the amplification of RSF1 is not only significantly correlated with tumor cell proliferation, migration, invasion and apoptosis abilities, but also with poor prognosis of patients with ovarian, lung, hepatocellular and prostate cancer (14-18).

Since the overexpression of PAK1 occurs in renal cancer (19), it was hypothesized that RSF1 may also be overexpressed in RCC. To the best of our knowledge, the present study has identified for the first time the expression status of RSF1 in RCC. Similar to other types of cancer (14-18), RSF1 overexpression was common, affecting $43.1 \%$ of RCC cases. The overexpression of RSF1 was associated with advanced clinical stages 
Table III. Multivariate regression analysis in predicting the survival of patients with renal carcinoma.

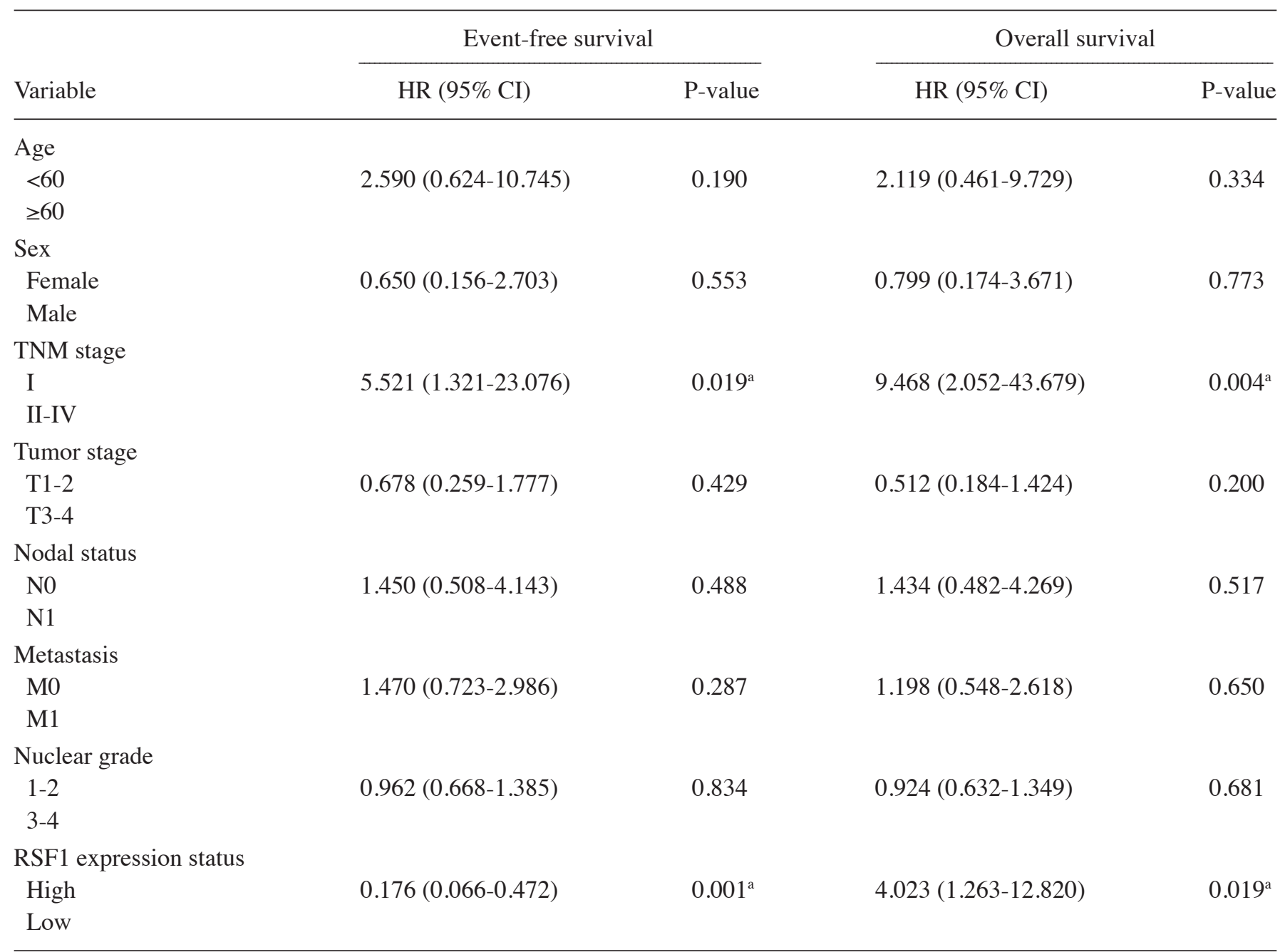

P-value was obtained using a $\chi^{2}$ test. ${ }^{a} \mathrm{P}<0.05$ is considered to indicate a statistically significant difference (two-sided). HR, hazard ratio; CI, confidence interval; RSF1, remodeling and spacing factor 1; TNM, tumor node metastasis.

and tumor stage in RCC. Notably, the Kaplan-Meier survival analysis indicated a statistically significant difference between patients with high and low RSF1 expression in their RCC stage and the long-term prognosis of high RSF1 expression cases appeared to be poorer compared with that of patients with low RSF1 expression. It was demonstrated that RSF1 expression was a predictive factor for tumor-free and overall survival.

The results of the present study indicated that the overexpression of RSF1 may indicate a poor prognosis in patients with RCC; therefore, it may be used as a novel prognostic marker. Davidson et al indicated that the compared with low expression of RSF1, overexpression and amplification of RSF1 predicted a decreased survival in patients with ovarian cancer (21), similar to Erb-B2 receptor tyrosine kinase 2 in breast cancer (27) and MYCN proto-oncogene, BHLH transcription factor in neuroblastoma (28). It is plausible that RSF1 gene amplification and overexpression in tumor cells disrupts the homeostatic kinetics in the chromatin remodeling machinery and alters gene regulation, consequently facilitating tumorigenesis (10,29,30).

In the present study, the association between high RSF1 expression and the prognosis of patients with RCC was analyzed. The results, suggesting that high RSF1 expression indicates a poor prognosis of RCC, are consistent with data in ovarian, prostate and hepatocellular cancer $(17,18,21)$. The results may be explained by previous studies demonstrating that RSF1 promotes tumor cell proliferation and invasion $(10,13,14,16)$. All of these results together suggest that RSF1 is an important oncogene in RCC. In addition, previous studies have demonstrated that RSF1 overexpression contributes to paclitaxel resistance in ovarian cancer cells, which may be a valuable direction of future studies in the area of kidney cancer.

To conclude, the results of the present study indicate that the patients with high RSF1 expression had more advanced clinical stages and a poorer prognosis compared with the patients with a low expression of RSF1. Future study will examine the mechanisms whereby RSF1 promotes a malignant phenotype, including tumor cell proliferation and drug resistance in RCC, since this may be a novel treatment target.

\section{Acknowledgements}

The present study was supported by the Scientific Research Fund of Liaoning Provincial Education Department, China (grant no. L2014318). 


\section{References}

1. Rini BI, Campbell SC and Escudier B: Renal cell carcinoma. Lancet 373: 1119-1132, 2009.

2. Gupta K, Miller JD, Li JZ, Russell MW and Charbonneau C: Epidemiologic and socioeconomic burden of metastatic renal cell carcinoma (mRCC): A literature review. Cancer Treat Rev 34: 193-205, 2008.

3. Hollingsworth JM, Miller DC, Daignault S and Hollenbeck BK: Five-year survival after surgical treatment for kidney cancer: A population-based competing risk analysis. Cancer 109 $1763-1768,2007$.

4. Ljungberg B, Bensalah K, Canfield S, Dabestani S, Hofmann F, Hora M, Kuczyk MA, Lam T, Marconi L, Merseburger AS, et al: EAU guidelines on renal cell carcinoma: 2014 update. Eur Urol 67: 913-924, 2015.

5. LeRoy G, Orphanides G, Lane WS and Reinberg D: Requirement of RSF and FACT for transcription of chromatin templates in vitro. Science 282: 1900-1904, 1998.

6. Loyola A, Huang JY, LeRoy G, Hu S, Wang YH, Donnelly RJ, Lane WS, Lee SC and Reinberg D: Functional analysis of the subunits of the chromatin assembly factor RSF. Mol Cell Biol 23: 6759-6768, 2003.

7. Ho L and Crabtree GR: Chromatin remodelling during development. Nature 463: 474-484, 2010.

8. Mao TL, Hsu CY, Yen MJ, Gilks B, Sheu JJ, Gabrielson E, Vang R, Cope L, Kurman RJ, Wang TL and Shih IeM: Expression of Rsf-1, a chromatin-remodeling gene, in ovarian and breast carcinoma. Hum Pathol 37: 1169-1175, 2006.

9. Yang YI, Ahn JH, Lee KT, Shih IeM and Choi JH: RSF1 is a positive regulator of NF- $\kappa \mathrm{B}$-induced gene expression required for ovarian cancer chemoresistance. Cancer Res 74: 2258-2269, 2014.

10. Zhao XC, An P, Wu XY, Zhang LM, Long B, Tian Y, Chi XY and Tong DY: Overexpression of hSNF2H in glioma promotes cell proliferation, invasion, and chemoresistance through its interaction with Rsf-1. Tumour Biol 37: 7203-7212, 2016.

11. Sanchez-Garcia F, Villagrasa P, Matsui J, Kotliar D, Castro V, Akavia UD, Chen BJ, Saucedo-Cuevas L, Rodriguez Barrueco R, Llobet-Navas D, et al: Integration of genomic data enables selective discovery of breast cancer drivers. Cell 159: 1461-1475, 2014.

12. Cheng CK, Chow LW, Loo WT, Chan TK and Chan V: The cell cycle checkpoint gene Rad9 is a novel oncogene activated by $11 \mathrm{q} 13$ amplification and DNA methylation in breast cancer. Cancer Res 65: 8646-8654, 2005.

13. Fang FM, Li CF, Huang HY, Lai MT, Chen CM, Chiu IW, Wang TL, Tsai FJ, Shih IeM and Sheu JJ: Overexpression of a chromatin remodeling factor, RSF-1/HBXAP, correlates with aggressive oral squamous cell carcinoma. Am J Pathol 178: 2407-2415, 2011.

14. Zhang X, Fu L, Xue D, Zhang X, Hao F, Xie L, He J, Gai J, Liu Y, $\mathrm{Xu} \mathrm{H}$, et al: Overexpression of Rsf-1 correlates with poor survival and promotes invasion in non-small cell lung cancer. Virchows Arch 470: 553-560, 2017.

15. Shih IeM, Sheu JJ, Santillan A, Nakayama K, Yen MJ, Bristow RE, Vang R, Parmigiani G, Kurman RJ, Trope CG, et al: Amplification of a chromatin remodeling gene, Rsf-1/HBXAP, in ovarian carcinoma. Proc Natl Acad Sci USA 102: 14004-14009, 2005.
16. Li Q, Dong Q and Wang E: Rsf-1 is overexpressed in non-small cell lung cancers and regulates cyclinD1 expression and ERK activity. Biochem Biophys Res Commun 420: 6-10, 2012.

17. Li H, Zhang Y, Zhang Y, Bai X, Peng Y and He P: Rsf-1 overexpression in human prostate cancer, implication as a prognostic marker. Tumour Biol 35: 5771-5776, 2014.

18. Xie C, Fu L, Xie L, Liu N and Li Q: Rsf-1 overexpression serves as a prognostic marker in human hepatocellular carcinoma. Tumour Biol 35: 7595-7601, 2014.

19. O'Sullivan GC, Tangney M, Casey G, Ambrose M, Houston A and Barry OP: Modulation of p21-activated kinase 1 alters the behavior of renal cell carcinoma. Int J Cancer 121: 1930-1940, 2007.

20. Meng ZW, Pan W, Hong HJ, Chen JZ and Chen YL: Modified staging classification for intrahepatic cholangiocarcinoma based on the sixth and seventh editions of the AJCC/UICC TNM staging systems. Medicine (Baltimore) 96: e7891, 2017.

21. Davidson B, Trope' CG, Wang TL and Shih IeM: Expression of the chromatin remodeling factor Rsf-1 is upregulated in ovarian carcinoma effusions and predicts poor survival. Gynecol Oncol 103: 814-819, 2006.

22. Roberts CW and Orkin SH: The SWI/SNF complex-chromatin and cancer. Nat Rev Cancer 4: 133-142, 2004.

23. Choi JH, Sheu JJ, Guan B, Jinawath N, Markowski P, Wang TL and Shih IeM: Functional analysis of 11q13.5 amplicon identifies Rsf-1 (HBXAP) as a gene involved in paclitaxel resistance in ovarian cancer. Cancer Res 69: 1407-1415, 2009.

24. Brown LA, Irving J, Parker R, Kim H, Press JZ, Longacre TA, Chia S, Magliocco A, Makretsov N, Gilks B, et al: Amplification of EMSY, a novel oncogene on 11q13, in high grade ovarian surface epithelial carcinomas. Gynecol Oncol 100: 264-270, 2006.

25. Hennessy BT, Nanjundan M, Cheng KW, Nolden L and Mills GB: Identification of remodeling and spacing factor 1 (rsf-1, HBXAP) at chromosome $11 \mathrm{q} 13$ as a putative oncogene in ovarian cancer. Eur J Hum Genet 14: 381-383, 2006.

26. Bostner J, Ahnström WM, Fornander T, Skoog L, Nordenskjöld B and Stål O: Amplification of CCND1 and PAK1 as predictors of recurrence and tamoxifen resistance in postmenopausal breast cancer. Oncogene 26: 6997-7005, 2007.

27. Borg A, Tandon AK, Sigurdsson H, Clark GM, Fernö M, Fuqua SA, Killander D and McGuire WL: HER-2/neu amplification predicts poor survival in node-positive breast cancer. Cancer Res 50: 4332-4337, 1990.

28. Rubie H, Hartmann O, Michon J, Frappaz D, Coze C, Chastagner P, Baranzelli MC, Plantaz D, Avet-Loiseau H, Bénard $\mathrm{J}$, et al: N-Myc gene amplification is a major prognostic factor in localized neuroblastoma: results of the French NBL 90 study. Neuroblastoma Study Group of the Société Francaise d'Oncologie Pédiatrique. J Clin Oncol 15: 1171-1182, 1997.

29. Shamay M, Barak O and Shaul Y: HBXAP, a novel PHD-finger protein, possesses transcription repression activity. Genomics 79: 523-529, 2002

30. Sheu JJ, Choi JH, Guan B, Tsai FJ, Hua CH, Lai MT, Wang TL and Shih IeM: Rsf-1, a chromatin remodelling protein, interacts with cyclin E1 and promotes tumour development. J Pathol 229: $559-568,2013$. 